\title{
A MEDIAÇÃO DE NOVAS TECNOLOGIAS DE INFORMAÇÃO NO TREINAMENTO COLABORATIVO
}

\author{
THE MEDIATION OF NEW INFORMATION TECHNOLOGIES IN \\ COLLABORATIVE TRAINING ${ }^{1}$
}

\author{
Jairit Garavit ${ }^{2}$ \\ https://orcid.org/0000-0003-1976-9891
}

1. ¿Este produto é o resultado do trabalho árduo de uma de suas Linhas de Pesquisa do projeto "Como deve pesquisar em Educação virtual e a distância?" do ano de 2021, realizada com Membros de forma interdisciplinar e interinstitucional (Professores - Alunos) da Pesquisa Seedbed: Sistemas Integrados de Gestão "Integradoss" Anexados ao GrupLAC: SIGCIENTY da Universidade Nacional Aberta e a Distância UNAD.

2. Engenheiro Industrial, Especialista em Educação Superior e à Distância, Mestre em Sistemas Integrados de Gestão HSEQ-RSC, Revisor de Pares da Elsevier, Revisor de Pares da Publons Academy e Advisor \& Peer Rewiever de Mendeley, Editor de Currículo em Revistas Acadêmicas - Minciencias. Líder da Seedbed de Pesquisa "Integradoss" e nomeado Professor Pesquisador da Escola de Ciências Básicas, Tecnologias e Engenharia ECBTI. Zona Caribenha, na Universidade Nacional Aberta e a Distância - UNAD. Email institucional Jairit.Garavit@unad.edu.co

Projeto de Pesquisa: ¿Cómo pesquisar em Educação virtual e a distância? 
Resumo: A colaboração é, sem dúvida, um tema da moda, um ponto de passagem obrigatório para um discurso política e pedagogicamente correto. $\mathrm{O}$ termo colaborativo tem ressurgido o interesse com o advento das ferramentas tecnológicas (TIC) e, principalmente, com o advento da chamada web 2.0. As ferramentas dos pontos sociais online são abundantes, seja para uso pessoal ou coletivo (no entanto, a elegância entre as duas está cada vez mais ausente: universos díspares colidem e se interpenetram) e incitam os beneficiários a colaborar muito. Mais. No mínimo, esses serviços incomparáveis impõem essa contingência de maneira poderosa. As TICs amotinaram e continuam a revolucionar a representação na qual existimos, procedemos e até ponderamos. Essa é a teoria que os pesquisadores defendem sobre a vivacidade coletiva. As trocas coletivas e o atendimento são uma parte integrante desse universo diferente. Este capítulo se concentrará no aspecto colaborativo dessas tecnologias de informação e comunicação: tentaremos definir o que é trabalho colaborativo e, em seguida, ver o que são práticas colaborativas: por um lado, entre educadores e, por outro, intrinsecamente a sala de estar. Finalmente, veremos como as TIC e, mais especificamente, certas ferramentas ou dispositivos podem promover o treinamento colaborativo. e a seguir ver o que são as práticas colaborativas: por um lado, entre educadores e, por outro, intrinsecamente na sala. Finalmente, veremos como as TIC e, mais especificamente, certas ferramentas ou dispositivos podem promover o treinamento colaborativo. e a seguir ver o que são as práticas colaborativas: por um lado, entre educadores e, por outro, intrinsecamente na sala. Finalmente, veremos como as TIC e, mais especificamente, certas ferramentas ou dispositivos podem promover o treinamento colaborativo.

Palavras chaves: Educação a distância, treinamento mediado, práticas colaborativas, NTICs,

Abstract: Collaboration is undoubtedly a fashionable topic, an obligatory stopping point for a politically and pedagogically correct discourse. The term collaborative has seen a resurgence of interest with the arrival of technological tools (ICT), and especially with the arrival of the so-called web 2.0. Online social points tools are abounding, whether for personal or collective use (however, the elegance between the two is increasingly lacking in the eye: disparate universes collide and interpenetrate), and they incite beneficiaries to collaborate a lot. more. At the very least, these incomparable services powerfully pose this contingency. ICTs have mutinied, and continue to revolutionize, the representation in which we exist, proceed and even ponder. This is the theory that researchers defend on collective vivacity. Collective swaps and attendance are a whole portion of this different universe. This current chapter will focus on the collaborative aspect of these information and communication technologies: we will try to define what collaborative work is, and then see what collaborative practices are: on the one hand, between educators and on the other intrinsically the living room. Finally, we will see how ICT and more specifically certain tools or devices can promote collaborative training.

Keywords: Distance Education, Mediated Training, Collaborative Practices, NICTs, 


\section{Introdução}

Nas últimas três décadas, os educadores reconheceram o valor do treinamento colaborativo. Os educadores reconhecem amplamente que os alunos não aprendem bem quando são recipientes isolados de conhecimento. Na verdade, os alunos devem superar o isolamento para aprender a escrever. Exercícios de treinamento colaborativo, como oficinas de revisão por pares, atribuições de pesquisa colaborativa, apresentações em grupo, artigos colaborativos e grupos de discussão, são componentes importantes de nossas salas de aula de treinamento porque incentivam a aprendizagem ativa, dando aos alunos a oportunidade de se envolverem mais profundamente com sua redação, e uns com os outros.

O treinamento colaborativo cobre um amplo território de abordagens com grande variabilidade na quantidade de tempo em sala de aula ou fora da sala de aula, construindo um ambiente de trabalho em grupo. As atividades colaborativas podem variar de discussões em sala de aula intercaladas com palestras curtas, em períodos inteiros de classe, a estudos de equipes de pesquisa de um ano. Os objetivos e processos das atividades colaborativas também variam amplamente.

Alguns membros do corpo docente elaboram atribuições para pequenos grupos em torno de etapas sequenciais específicas ou tarefas estruturadas de perto. Outros preferem uma agenda mais espontânea que se desenvolve a partir dos interesses ou dúvidas dos alunos. Em alguns ambientes de treinamento colaborativo, a tarefa dos alunos é criar um produto claramente delineado; Em outros, a tarefa não é produzir um produto, mas sim participar de um processo, um exercício de resposta ao trabalho de outros ou de participação na análise e na criação de sentido.

Um conjunto de tecnologias de computador e telecomunicações, incluindo videoconferência de desktop, groupware e sistemas de Internet / intranet estão evoluindo para formar a estrutura básica de um novo local de trabalho, que não é limitado pela geografia, tempo e limites organizacionais.

Aprendizagem mediada por tecnologia foi definida como um curso de treinamento (ou seja, reciprocidade de informação, interpretação e codificação em um modelo mental) entre pares e / ou professores que são mediados pelo uso de novas tecnologias de comunicação (TIC). As TICs têm sido utilizadas para apoiar ações de formação e aprendizagem primária em universidades que implementam EAD e organizações que realizam projetos por meio de equipes geograficamente dispersas. Em ambos os contextos, os alunos mediados pela tecnologia se envolvem na aprendizagem em equipe que dá origem ao conhecimento que é então usado na execução da tarefa. 
Percebendo o papel do treinamento no trabalho em equipe colaborativo, uma abordagem de análise de processo (ou seja, fala e avaliação do comportamento) foi adotada na pesquisa de aprendizagem em grupo de alunos. Ao observar diretamente os comportamentos de aprendizagem, pode-se identificar exatamente como a questão do treinamento dos alunos é melhorada ou limitada.

O objetivo deste capítulo é estender a pesquisa atual sobre o desempenho do aluno mediado pela tecnologia, examinando os efeitos do modo de colaboração mediado pela tecnologia nas interações da equipe durante o trabalho colaborativo.

\section{Inteligência coletiva}

Antes de abordar o treinamento colaborativo, achamos interessante relembrar algumas noções relacionadas à inteligência coletiva e o que as TIC podem contribuir. Para Lévy, é absolutamente necessário nos inventarmos coletivamente como espécie (Lévy, 1997) e o vínculo social é fundamental para construir essa inteligência coletiva. Ele acredita que as TICs oferecem uma oportunidade incomparável de criar ou, pelo menos, melhorar esses links. A inteligência coletiva não é uma fusão de inteligências individuais, mas algo mais elaborado. O Homo sapiens tornou-se homo comunica. Esse conhecimento de um novo tipo seria o motor de uma nova civilização, convidando os leitores a falar sobre projetos em conexão com as novas tecnologias ao invés de raciocinar em termos de impactos, o que implicaria passividade diante dessas novas tecnologias.

O otimismo de Lévy ou Surowiecki (2008) em relação à evolução, ou revolução, em curso não é compartilhado por todos. Alguns como Breton (2001) preferem ver esse desenvolvimento com muito ceticismo (fala do novo culto da Internet), outros como Pagisani e Piotet (2008) têm mais nuances e preferem falar da alquimia das multidões, temos passou de um estado de usuário passivo de internauta (recebendo informação em páginas estáticas) ao de ator web (ator comprometido que participa da melhora de anexos na web, graças a tecnologias dinâmicas e múltiplas redes). Para os dois pesquisadores, é mais uma mudança de práticas do que de ferramentas.

Portanto, Gharsallah (2007) se limita a distinguir três tipos de inteligência:

- A inteligência coletiva original, que consiste em reunir várias inteligências individuais. Isso requer proximidade espacial, um contrato social e uma arquitetura que pode ser polimórfica entre os indivíduos.

- Inteligência piramidal, que surgiu com a chegada da escrita. Cada um é especializado. Essa inteligência é baseada na divisão do trabalho, na divisão do acesso à informação e em um princípio de autoridade (há um líder). 
- Inteligência de enxame, como o que acontece em alguns insetos. Os indivíduos não têm um quadro geral, não mostram inteligência no nível individual, mas no coletivo ela se torna inteligente.

A Internet pode estar na origem de uma quarta inteligência com possibilidades de compartilhamento de conhecimento, redes horizontais, hipertextualidade, interatividade e conectividade permanente. Quando esses autores falam em inteligência coletiva, surge a ideia de compartilhamento, de coletivo, de co-criação; subjacente à noção de colaborativo.

\section{Histórico de treinamento colaborativo}

Se os termos Treinamento, aprendizagem ou ensino colaborativo são muito populares com o surgimento das TIC, deve-se notar que é anterior ao mundo digital. O trabalho de Piaget, mais vinculado à aprendizagem cooperativa (Baudrit, 2005), já carregava as sementes da formação colaborativa (Baudrit, 2007). Para Baudrit, o treinamento colaborativo tem sua origem em quatro áreas:

- Psicologia com a contribuição de Piaget:O treinamento colaborativo promove o conflito sócio-cognitivo, necessário ao treinamento, na medida em que os alunos são autônomos e iguais no desempenho de suas tarefas. Piaget falou de aprendizagem cooperativa, porém, Baudrit a associa mais ao treinamento colaborativo.

- Psicologia nas pegadas de Vygotsky:as crianças aprendem conhecendo seus colegas; as interações promovem o conhecimento. Bruner, Cole, Rogoff ou Williams destacam o papel dos pares. Aqui encontramos o conceito de Zona de Desenvolvimento Proximal (ZDP) proposto por Vygotsky.

- Sullivan's Psychiatric Stream (1953): Ele irá preencher a lacuna entre o contexto individual e o social.

- Filosofia, com Dewey: filosofia pessoal focada no vínculo entre as pessoas, que respeita ou destaca as habilidades dos outros.

No entanto, verifica-se no livro de Baudrit (2007) que existem várias concepções de formação colaborativa. As abordagens norte-americana e europeia colidem. A orientação europeia deve muito a Piaget. Trata-se de colaboração contraditória, onde o foco está no processo cognitivo. Não é tanto o resultado final que importa, mas o raciocínio, o progresso dos alunos. A autonomia dos sujeitos é essencial. Ao contrário, na concepção norteamericana, a resolução da tarefa é fundamental. É uma colaboração construtiva.

O grupo é organizado previamente, pelo professor ou formador, cada um com uma função definida a cumprir, enquanto, para os europeus, o grupo é autónomo e se constrói ao longo do percurso. 
Ao invés de se opor a essas duas concepções, Baudrit prefere colocá-las no mesmo eixo, no mesmo continuum que iria de um modelo funcionalista (norte-americano) a um modelo genético (europeu). Desta forma, o professor pode colocar o cursor onde quiser neste eixo. Em todos os casos, a atividade está no centro do sistema. Porém, o treinamento colaborativo não é simples, não pode ser decretado. Certas condições são necessárias. Em particular, o desenvolvimento de conhecimentos técnicos que possibilitem o ingresso neste tipo de formação. Não podemos decretar o estabelecimento de situações de formação colaborativa sem ter dedicado tempo a técnicas e metodologias adequadas. Apesar de suas vantagens inegáveis, especialmente do ponto de vista sócio-construtivista, o treinamento colaborativo não é necessariamente a melhor solução para todos os tipos de aprendizagem. Baudrit especifica que esta forma de trabalhar é mais útil para a aprendizagem não fundamental, que se presta mais ao raciocínio e à reflexão.

\section{Observações de treinamento colaborativo}

Apesar dos esclarecimentos que fornecemos no parágrafo anterior, não há uma definição com a qual os pesquisadores tenham concordado. $O$ treinamento colaborativo pode assumir uma ampla variedade de aspectos. Dillenbourg (1999) afirma que é muito difícil dar uma definição precisa. O próprio termo treinamento colaborativo é questionável. Dillenbourg o sugere e pudemos lhe explicar da seguinte forma: Situação em que se esperam formas particulares de interação entre as pessoas, que devem ativar mecanismos de aprendizagem, sem que essas interações realmente ocorram. Além disso, se propõe a lançar flashes que poderiam ser interpretados como ocorridos neste capítulo, e que se pretendem mínimos: um contexto em que dois ou mais indivíduos vivenciam, ou pretendem treinar, em temas aplicados, com toda a latitude de interpretação que os termos dois ou mais permitem, para aprender algo e aprender juntos.

No entanto, esta definição deliberadamente vaga é compartilhada: Falaremos de trabalho colaborativo, treinamento ou aprendizagem quando os alunos tiverem que resolver um problema ou desenvolver um conhecimento complexo juntos. Ele cita duas condições para os alunos embarcarem no caminho da formação colaborativa: o grupo deve ter objetivos e necessidades semelhantes; e deve compartilhar valores comuns. Ele cita duas condições para os alunos embarcarem no caminho da formação colaborativa: o grupo deve ter objetivos e necessidades semelhantes; e deve compartilhar valores comuns. Ele cita duas condições para os alunos embarcarem no caminho da formação colaborativa: o grupo deve ter objetivos e necessidades semelhantes; e deve compartilhar valores comuns.

Ainda assim, uma situação é considerada colaborativa quando é interativa, síncrona e negociável entre pares. De acordo com pesquisas mais recentes sobre práticas digitais, a questão da sincronia não parece mais relevante. 
Manderscheid e juventude (2007) adotam a definição de treinamento colaborativo: Treinamento colaborativo é um processo ativo pelo qual o aluno trabalha para construir seu conhecimento. $\mathrm{O}$ formador desempenha o papel de facilitador da aprendizagem enquanto o grupo participa como fonte de informação, como agente de motivação, como meio de ajuda e apoio mútuos e como lugar privilegiado de interação para a construção agrupada do conhecimento. A abordagem colaborativa reconhece a natureza individual e reflexiva da aprendizagem, bem como sua ancoragem social, conectando-a às interações em grupo. Na verdade, a abordagem colaborativa combina duas abordagens: a do aluno e a do grupo. Aqui aparece claramente o papel-chave do professor-tutor, papel que é proposto por muitos pesquisadores,

Baudrit, por sua vez, estabeleceu uma tipologia e distinguiu vários graus de colaboração para uma tarefa de escrita coletiva:

- Co-redação: colaboração do início ao fim, para cada etapa da tarefa.

- Coedição: colaborações ad hoc baseadas em textos individuais para uma realização comum.

- Co-respondendo: colaboração limitada a revisões de artigos escritos individualmente.

- Coeditar: colaboração apenas para correção final.

- Assistência escrita: colaboração apenas quando necessária (não sistemática).

Vemos então que a abordagem colaborativa pode ser múltipla e referir-se a práticas bastante diversas. Pode ser total ou episódico, ao longo do processo ou em momentos específicos.

\section{Definições: Coletiva, Cooperativa, Colaborativa}

Todos os três termos são amplamente usados na literatura. Vimos que o termo colaborativo possui vários significados. Essa dificuldade em defini-lo às vezes é uma fonte de confusão. Alguns escritos nem sempre distinguem claramente entre o que é colaborativo e o que é cooperativo. Baudrit alerta para uma possível confusão. Para ele, a diferença essencial tem a ver com o choque de ideias: no treinamento colaborativo colidem ideias divergentes, o que não ocorre no treinamento cooperativo.

Para Bruner, o treinamento colaborativo requer a capacidade dos atores de ler os pensamentos dos outros, ou seja, de atingir o espaço de perspectiva de outros alunos, para progredir. O resultado não é previsível, nunca é certo, enquanto, para a formação cooperativa, Wijnen (2001) considera que a formação colaborativa faz parte de uma abordagem construtivista, enquanto a formação cooperativa corresponde mais a uma aprendizagem mais 
tradicional, em que a autoridade do professor está sempre presente. No entanto, essa distinção nem sempre é relevante na prática.

Lembrando que o conceito de inteligência coletiva foi definido por Lévy (1997). Para ela, esse conceito geralmente se refere à capacidade das comunidades humanas de evoluir para uma organização com alto nível de complexidade e integração por meio da colaboração e da inovação. $O$ termo coletivo se refere a um campo muito mais amplo no qual os conceitos de cooperativo e colaborativo são particularmente relevantes. Portanto, às vezes pode ser mais adequado descrever a realidade das práticas.

Para Michel, Garrot e George (2007), o treinamento colaborativo é utilizado para promover a aprendizagem individual a partir das interações entre os alunos. Se as plataformas digitais de hoje oferecem ferramentas interessantes de comunicação, produção, compartilhamento e trabalho colaborativo, acreditam que não são realmente utilizadas. Seu estudo (que focou em situações de aprendizagem coletiva implementadas no ensino superior) compara o que é prescrito pelo professor com o que é feito de fato. O trabalho planejado é geralmente coletivo, mas é mais frequentemente cooperativo do que colaborativo por natureza. No entanto, os resultados devem ser moderados, a ponto de os atores às vezes terem dificuldade em distinguir entre as duas abordagens.

\section{Contradições das NTICs}

As tecnologias de comunicação, às vezes ainda chamadas de novas, trouxeram grandes mudanças na forma como trabalhamos, vivemos e somos. Para Mallein (2009), entramos em um mundo de contradições ou paradoxos. São oito relacionados às TIC, vamos manter apenas quatro para o nosso tópico. As relações que temos com os outros, com o tempo, com o espaço e com a organização mudaram.

- O paradoxo de em comparação com os outros: vivemos juntos e separados. Assim como essa multidão relâmpago (mobilizações flash de multidões no mundo real), iniciada na Internet (mundo virtual), onde todos participam de um movimento coletivo enquanto tocam sua própria partitura, fazemos parte de um coletivo sem nos dissolvermos nesse coletivo.

- O paradoxo de em relação ao tempo: concordamos em perder tempo para ganhar algo. Esse fenômeno assumiu uma escala sem precedentes com a Internet.

- O paradoxo de em relação ao espaço: mudou profundamente. Antes, para fazer parte de uma rede, para colaborar, era necessária a proximidade geográfica, ou demorava para se comunicar pelo correio. Não é mais o caso: a tecnologia digital nos permite transcender o espaço e o tempo. $\mathrm{O}$ mundo físico e o mundo digital se alimentam um do outro. 
- Da mesma forma, informando a organização: Ações antecipadas e preparadas são cada vez mais impulsionadas por organizações de última hora. As TICs modificam a temporalidade, podemos ser reativos em tempo real sem estarmos juntos.

Essas mudanças, esses paradoxos mudam a norma social do comportamento individual. Precisamos levar essas mudanças em consideração para explicar em parte o que diremos sobre o trabalho colaborativo. O termo colaborativo tem hoje as mesmas características de ontem? Levy (1997) vê outro tipo de paradoxo: quanto mais universal é o ciberespaço (estendido, interconectado, interativo), menos totalizável ele é. Reconhecemos o otimismo do autor, que vê neste novo espaço a promessa de uma renovação democrática, a chegada de novos cidadãos. Michel Cucchi (2003) modera o ponto e pensa ao invés de More [o ciberespaço] é extenso, interconectado, interativo, e esse universo virtual se impõe como um novo campo de batalha contra qualquer tentativa de totalização. Em outras palavras, a terra fica em uma estepe,

Encontramos a tese defendida por Pisani e Piotet (2008). Existem ainda outros paradoxos em torno das TIC, na área que mais nos interessa: a educação. Esse paradoxo está mais presente em todos os países desenvolvidos e nos que estão por aqui e ainda estão em subdesenvolvimento.

Segundo Chaptal (2007), a evolução dos usos das TIC (que difere das práticas ou usos) na sala de aula é muito lenta, embora os professores as tenham adotado em massa também para o trabalho de preparação das aulas. usar. As TICs não fazem parte das práticas de sala de aula. $\mathrm{O}$ mesmo acontece, segundo ele, com os professores de inglês, apesar da boa imagem que transmitem nos países desenvolvidos nessa área: de fato, as escolas estão bem equipadas, principalmente com lousas interativas, mas os usos são limitados. Além disso, embora muitos atores proponham o aspecto colaborativo, parece que os usos nas escolas ainda são usos individuais, mas não sociais. ¿A educação teria dificuldade em integrar as especificidades das TIC?

\section{Experiências colaborativas e TIC}

Um exemplo de colaboração eficaz usando TIC é a pesquisa internacional que foi realizada para descobrir as toxinas garantidoras do vírus da gripe aviária: SARS. A OMS pediu a vários laboratórios (treze ao todo), localizados em dez países diferentes, para embarcar nesta pesquisa, sem impor de antemão um quadro. Cada laboratório trabalhou de forma independente, mas todos se reuniram por videoconferência todos os dias para fazer um balanço de seus respectivos progressos. Compartilhar as descobertas de alguns, levando em consideração o progresso de outros, permitiu que o vírus fosse atualizado em apenas algumas 
semanas. Este é apenas um exemplo, em um campo bastante distante da educação, mas bastante representativo nos últimos tempos do mundo glocalizado em que vivemos,

As novas tecnologias de comunicação e colaboração. O nome não parece oficial, mas é indicativo da evolução dos usos da Internet. Chaptal (2007) parece compartilhar esse ponto de vista quando escreve que a web colaborativa é muito promissora: Quer se chame de web 2.0, 3.0, 4.0, web colaborativa ou redes sociais para sacrificar a moda, a orientação atual para usuários, professores ( e alunos) criar conteúdo e compartilhá-lo com seus colegas atende às profundas expectativas dos educadores. O velho sonho dos pioneiros da tecnologia educacional se torna realidade.

\section{Construindo conhecimento em treinamento em TIC Colaborativa}

O projeto carro-chefe da construção coletiva do conhecimento é a enciclopédia online gratuita Wikipedia. (Endrizzi 2006) dedicou um arquivo de resumo. Feyfant, (2006). A construção desta enciclopédia é amplamente colaborativa e é possível através do uso de um mecanismo wiki. A colaboração, neste caso, é o resultado de pessoas que não necessariamente se conhecem, que provavelmente nunca se encontraram ou se conheceram, nem física nem virtualmente. A motivação é o produto final, em constante evolução. Este é um exemplo de inteligência coletiva (Lévy, 1997).

A fundação Wikimedia na origem da Wikipedia tem outros projetos colaborativos em andamento: o projeto wiki-books para a criação e distribuição de recursos educacionais gratuitos, wiki-commons-multimedia file bank) e outros, todos baseados no mesmo conceito colaborativo.

Esses projetos contam a base de conhecimento acumulada, mas também vale a pena citar os projetos de construção (ou melhor, de compilação) de memória, citando, por exemplo, o que estava em curso na metrópole de Brest com o projeto Wiki-. Brest - Os residentes são convidados a enviar sua (s) história (s), que fazem parte da história de uma área geográfica. $\mathrm{O}$ acervo desses arquivos pessoais nos permite construir uma memória coletiva. $\mathrm{O}$ aspecto colaborativo pode ser percebido tanto no acúmulo de ensaios individuais, no Networking dessas contribuições, quanto no estabelecimento de um trabalho intergeracional onde os mais jovens vêm ajudar os idosos ou menos familiarizados com as TIC a colocar em palavras e online o que eu. tem que dizer.

Estamos nos afastando do campo da docência, mas essas experiências de construção do conhecimento e da memória devem encontrar eco no campo educacional. O paralelo pode

ser traçado com o conceito de Produzir - Desenvolvido por Bruns (2007): Produzir tanto no 
usuário quanto no produtor de informações na Internet. Não produzimos conteúdo da forma tradicional, mas sim de forma colaborativa e contínua.

\section{Mundos educacionais em colaboração com Tics}

A realidade da colaboração entre professores é apreciada de diferentes maneiras, mas diferentes pontos de vista não são necessariamente opostos. Eles são a representação da diversidade de situações no mundo educacional. A formação colaborativa entre professores não esperou pela chegada das TIC para se desenvolver. Gueudet e Trouche (2009) tomam o exemplo da associação Sésamath que é pioneira neste campo (colaboração e utilização das TIC), mas que faz parte de uma história de colaboração significativa entre professores de matemática, em particular através do IIE \& M ( institutos de pesquisa em educação matemática) desde 1969. Portanto, ele acrescenta que, se as práticas de ensino colaborativo são realmente antigas, as TIC lhes dão muito mais alcance e eco, as TIC tornam a colaboração muito mais fácil de implementar, conforme evidenciado pela revisão, entre outros. Referências do IIE \& M, particularmente no artigo sobre pesquisa colaborativa de problemas em matemática (Sauter, 2008).

A existência de listas de discussão por e-mail especializadas em disciplinas já existe há muito tempo, seja sob responsabilidade de instituições (muitas vezes academias), ou mais informalmente, por iniciativa de um ou mais professores. Esses espaços costumam servir como locais informais de confronto de ideias e co-formação, principalmente no que diz respeito às TIC (Gueudet e Trouche, 2009). Os professores adotam uma atitude prática reflexiva e melhoram suas práticas graças ao enriquecimento proporcionado por seus colegas. Em seguida, o panorama associativo educacional se recompõe com a chegada de novas associações de professores cujo objetivo é a criação de recursos de forma colaborativa.

Gueudet e Trouche (2009) estudaram a evolução dessas associações, verifica-se que a ideia de colaboração foi sendo construída aos poucos. Inicialmente houve um desejo de mutualização (agrupamento de recursos oferecidos individualmente) que evoluiu para uma necessidade de cooperação (projeto comum em que cada pessoa garante uma participação predeterminada; agrupamento de produções leva a um produto final). Alguns em particular criaram projetos verdadeiramente colaborativos (cada tarefa do projeto é realizada coletivamente, por meio do jogo de revisão, verificação, etc.). Quando os atores são questionados, eles geralmente usam os termos "trabalhando juntos". Aqui encontramos a falta de clareza entre o que faz parte da cooperativa e o que é colaborativo.

A colaboração também pode durar além da conclusão do recurso proposto. Na verdade, o design de um recurso continua com o uso, o recurso não é congelado e se torna mais rico à medida que é usado. Eles assumem uma forma comum (em evolução), o que facilita a 
colaboração. (Gueudet e Trouche, 2009). Isso deve ser visto em paralelo com o projeto deste capítulo, que tirou o equilíbrio desse desenvolvimento.

(Chaptal 2009) permanece cético apesar de tudo sobre a realidade da colaboração entre professores: se no início de um projeto muitas pessoas são voluntárias, parece que no final, apenas uma minoria dos atores realmente se envolve em um projeto colaborativo. E entre as possibilidades colaborativas oferecidas pelas ferramentas, são utilizadas apenas as funcionalidades básicas, que de forma alguma são colaborativas: disponibilização de documentos, agenda, atas de reuniões. No entanto, isso não significa que não haja colaboração. Na verdade, a colaboração pode existir, mas ferramentas ou formulários mais tradicionais são usados. Não é porque as TIC não são usadas que não há colaboração, as ferramentas não fazem colaboração,

É interessante estudar casos, porque mostram uma política pró-ativa em TIC. Segundo Chaptal, a competição entre os estabelecimentos é um obstáculo à colaboração. Embora exista colaboração entre professores, ela permanece limitada à escala de um estabelecimento. Desde então, não é compartilhado ou trocado com outros estabelecimentos.

Existe também um outro tipo de colaboração, que surge fora dos círculos mais ou menos oficiais ou organizados em associações, a partir de iniciativas individuais. Ferramentas de mídia social na Internet, especialmente em torno da plataforma, são usadas para desenvolver comunidades temáticas. Podemos citar e alfabetizar na mídia da Internet, por exemplo, Sala de Aula 2.0 (em inglês), Ensino de Ciências (para a escola primária), Escola Extramural (internacional) e muitos mais. Nessas redes dedicadas nascem discussões e debates, por meio de blogs ou fóruns interpostos e, às vezes, estão na origem de um trabalho verdadeiramente colaborativo em wikis. Sessões de co-treinamento online são organizadas, geralmente sobre o uso de software específico que pode ser do interesse dos professores em suas práticas de sala de aula. Isso tudo é autogerido, algumas redes adicionam várias centenas de participantes. Também aqui os participantes desenvolvem práticas reflexivas sobre o seu trabalho.

Vimos que as TIC foram o fator importante para apoiar a formação colaborativa entre professores. Mas o resultado desse trabalho colaborativo pode esbarrar no problema do copyright: como reaproveitar recursos, modificá-los e redistribuí-los (círculo virtuoso) sem violar os honorários do autor e a lei de copyright? A OCDE publicou em 2007 vários relatórios solicitando a adoção de licenças abertas para criar recursos educacionais gratuitos (REA em inglês: Recursos Educacionais Abertos). Os direitos autorais devem ser adaptados para se alinhar às ferramentas atuais. As licenças Creative Commons foram criadas para atender a essa necessidade (nem todas são licenças gratuitas, mas todas permitem distribuição legal). As universidades seguiram os passos do MIT e oferecem seus cursos online sob licenças gratuitas, grandes projetos como: Software Livre para Educação e um livro para 
instrutores foi publicado para encorajar o desenvolvimento de REA (Guell e Wiley, 2008). Essas novas licenças são uma contribuição valiosa para o desenvolvimento de práticas colaborativas.

\section{Experiências colaborativas: ferramentas de rede, blogs, wikis.}

Uma questão recorrente refere-se aos efeitos de tais práticas entre os professores nas opções pedagógicas. Ou seja, o fato de desenvolver recursos educacionais de forma coletiva, ou mesmo colaborativa, afeta a organização educacional em sala de aula? Os professores colaboradores estabelecem situações de treinamento colaborativo? Perguntas como essa costumam ser recorrentes e levantadas durante reuniões na Internet. cujo tema foi: Como coproduzir e organizar recursos?

A resposta é complicada. Assim como os professores são grandes usuários das TIC para preparar suas aulas sem realmente usá-las com seus alunos, as práticas colaborativas para desenvolver recursos não necessariamente se transferem para as práticas de sala de aula. Ainda há pesquisas científicas sobre esses assuntos. A maioria se refere a medidas relacionadas ao ensino superior.

Moiraud (2009) desenvolve um treinamento colaborativo graças à tecnologia digital, pedindo a seus alunos que mantenham um blog (que ele assimila a um espaço de treinamento e imersão digital). Para ele, tal dispositivo vai contra os hábitos acadêmicos dos alunos, mais familiarizados com o ensino transmissivo, que demanda um tempo significativo para a aquisição de ferramentas e procedimentos. Aqui, a formação colaborativa é tanto um meio de realização de projetos, como um fim na medida em que se trata de apropriação do saber que os alunos devem utilizar em situações profissionais.

Moiraud não se opõe a abordagens colaborativas e transmissivas, elas se complementam: “a formação colaborativa é muito exigente, exige que os envolvidos no processo de aprendizagem sejam permanentemente ativos, mudem seus hábitos, mobilizem novas competências (tecnológicas, jurídicas, regulatórias, editoriais Não elimina os outros modos de organização da sala de aula, não proíbe o transmissivo, não se substitui, se acrescenta.

A dificuldade de os alunos ingressarem em um processo de formação colaborativa, mencionada por Moiraud, também é apontada por Dumont (2007): As habilidades exigidas pelo trabalho coletivo não são inatas; são adquiridos gradualmente pelos alunos, em particular através de:

- Cenários de aprendizagem que favorecem o trabalho coletivo e se adaptam à própria natureza da formação ou disciplina. 
- Apoio metodológico e organizacional.

- Orientação na escolha das ferramentas de comunicação.

Bachand (2009) em um arquivo online em seu site, dedicado a blogs em um ambiente educacional, discute o interesse dos alunos em manter um blog pessoal. Isso permite chegar ao seu raciocínio, basear as fases de uma etapa ou de um plano de longo prazo. Esta ferramenta ajuda os alunos a abraçarem assim uma condição reflexiva sobre o seu ensino, sobre as suas capacidades, pode promover a metacognição. Ducate e Lomicka (2008) mostram o particular interesse que o blog pode ter em uma aula de idiomas, em especial promovendo a visita de outros blogs de diferentes culturas, e criando links entre blogs.

Essa complexidade da organização, esse acúmulo de conhecimentos e habilidades que devem ser dominados podem explicar os obstáculos para a adoção dessa abordagem colaborativa pelos professores. Este é também o ponto de vista de Siméone, Eneau e Rinck (2007) sobre cenários de treinamento colaborativo a distância: Para um professor que geralmente está integrado em um dispositivo de aprendizagem presencial e essencialmente transmissivo, o progresso e a execução de um rush in Seu treinamento online colaborativo, portanto, levanta muito mais questões do que traz à mente. Os trabalhos de Nussbaumet al. (2008) também mostram que a formação colaborativa em sala de aula não é muito difundida, e o modelo operacional professor / aluno continua sendo o ponto de referência para muitos.

Os sites que usam um mecanismo wiki parecem ser emblemáticos dos recursos de colaboração da Internet de hoje. Existem outras ferramentas, que geralmente são inspiradas na forma como os wikis funcionam. Buffa (2008) dá uma definição do termo wiki, que pode se referir tanto ao software de gerenciamento de conteúdo quanto ao próprio site (portanto, às vezes há alguma confusão): Um wiki é um site coletivo no qual um grande número de participantes pode editar páginas e criar novos usando o navegador da web. O primeiro wiki data de 1995, inventado por Ward Cunningham. Esta nova forma de criar conteúdo revolucionou o uso: $\mathrm{O}$ conceito teve um triunfo, um impacto, que realmente ajudou a mudar a visão da Internet moderna, transformando-a em um meio para escrever e colaborar facilmente.

Buffa explica o sucesso dessa ferramenta pelo fato de o wiki ser um software relacional ou social de um novo tipo, relativamente fácil de usar. Por outro lado, mais uma vez, não é a ferramenta que faz a colaboração: para haver uma colaboração efetiva é necessário ter uma comunidade disposta a colaborar e pessoas que dêem vida a esta comunidade (é o que ele chama de cultivar seu wiki). Exploraremos esse aspecto relacional mais adiante no capítulo, quando discutirmos o papel dos instrutores na educação online ou virtual.

Os wikis são de fato uma plataforma interessante para treinamento colaborativo. $\mathrm{Na}$ estrutura dos estudos revisados, o wiki foi usado para várias funções: recursos do curso, 
fórum e glossário. Só a realização do glossário foi realmente elaborada em colaboração pelos alunos, também é o projeto que funcionou melhor. É de notar que também existiam problemas de classificação, que inevitavelmente influenciavam a participação dos alunos e brincavam com a sua motivação. Dito isso, os artigos e pesquisas revisados em wikis mostram os dois termos cooperativo e colaborativo, sem necessariamente distinguir entre os dois. Durante a análise, percebeu-se que os alunos demonstraram grande interesse na produção de outros alunos.

Ferris e Wilder (2001) lançaram uma luz interessante sobre o valor de usar um wiki em sala de aula. Tendo retomado a distinção feita por Prensky (2001) Digital Origins and Digital Arrivals (Oposição refutada em outro lugar por Danah Boyd - entrevistado em Piotet e Pisani, 2008), os autores fazem uma breve história: antes da quimera de $\mathrm{Na}$ imprensa, o discernimento era transmitido oralmente, antes de ser estabilizado pela escrita. Assim, passamos de um sistema de ensino baseado na transmissão oral para um sistema escrito que tem permitido reforçar conhecimentos, saberes e contribuído para o aprimoramento da reflexão abstrata e analítica. Porém, a chegada da eletrônica e da multimídia nos levou a uma nova era da oralidade, ou melhor, a uma era de uma nova oralidade. Os autores usam os termos do paradigma de impressão e paradigma secundário-oral baseado em digital. Para eles, o wiki permite vincular esses dois paradigmas no mesmo continuum: Todos esses usos e potencialidades dos wikis são baseados nos pontos fortes do modelo impresso, ao mesmo tempo em que incorporam os pontos fortes do modelo oral secundário.

No entanto, os sistemas educacionais não acompanharam essa mudança, daí uma tensão entre o que se faz na escola e o que se faz fora dela: a escola continua a vincular o saber e a escrita. $\mathrm{O}$ modelo de impressão ainda é predominante. $\mathrm{O}$ fato de não poder ter controle absoluto sobre o conteúdo postado online explica a relutância dos educadores em enfrentar essas ferramentas. No entanto, um wiki mantém registro de todas as mudanças e, assim, permite que os professores identifiquem quais estratégias de aprendizagem são as mais apropriadas. É preciso também aceitar as interações entre os alunos, a coconstrução do conhecimento. Como dissemos na introdução, os wikis podem apoiar uma abordagem sócioconstrutivista.

Essa também é a tese defendida por Cress e Kimmerle (2007) e de Mejías (2006). Assim como Ferris e Wilder (2001), eles acreditam que os wikis proporcionam, por um lado, novas oportunidades de aprendizagem e construção colaborativa de conhecimento. Mas, por outro lado, também nos permitem entender o que está em jogo no processo de aprendizagem. Para eles, há uma ligação entre a teoria dos sistemas de Luhmann e a teoria da cognição de Piaget: há uma interface entre um sistema social semelhante a um wiki e o sistema cognitivo de um indivíduo. 
Para Mejías (2006), as TICs preparam os alunos para participarem de redes onde o conhecimento é construído e compartilhado coletivamente. O tempo e o espaço escolar são fragmentados, comunidades de aprendizagem são criadas e ganham vida fora do horário escolar.

Não discutiremos aqui a utilização de ferramentas de networking de pessoas, como o Facebook, em um quadro educacional, ferramentas que os mais jovens vêm adotando no dia a dia. Não há pesquisas específicas sobre o uso dessas ferramentas; No entanto, existem alguns relatos raros de experimentos, principalmente na América do Norte. A tese de Boyd (2008) é uma das primeiras a estudar de perto as práticas de adolescentes nas ferramentas de mídia social digital, mas não aborda o aspecto colaborativo.

Essas ferramentas usadas por alunos e professores resultam em uma redefinição de funções. Educadores e alunos se encontram no papel de produtores de conteúdo. O professor não é mais a única autoridade que pode publicar, e deve aceitar que o que o aluno publica não corresponde ao que ele esperava. Vimos que isso é inerente ao treinamento colaborativo, mas o efeito é ampliado com o uso das TIC. No entanto, Mejías (2006) insiste na necessidade de preservar espaços fechados para os alunos, que não são visíveis do exterior, para que possam ter discussões reservadas, de forma a não sofrerem demasiada pressão em relação ao que é publicado. As fronteiras estão se confundindo, mas às vezes é preciso saber como restabelecê-las para que o aprendizado não seja penalizado.

\section{Dúvidas essenciais da formação colaborativa mediada por Tics}

Siméone Eneau e Rinck (2007) analisaram um cenário de treinamento colaborativo a distância e online (no campus da Universidade da França). De todas as unidades oferecidas, apenas uma minoria implementou treinamentos colaborativos. Eles explicam a relutância dos professores em desenvolver uma sequência completa usando situações de treinamento colaborativo pelo fato de que "Para um professor que geralmente está integrado em um sistema de aprendizagem presencial e essencialmente transmissivo, o processo e a execução de uma atividade de treinamento colaborativo Online portanto, levanta muito mais questões do que levanta. Essa relutância, explicada em particular pelo desconhecimento do assunto, também é analisada por Montuoriet al. (2008) (pesquisa com professores do ensino superior para os quais a ferramenta informática faz parte da formação que devem proporcionar). Eles apontam a necessidade de treinamento e apoio para o uso educacional das TICs.

Ven e Rioux (2002) analisaram cenários de integração pedagógica de TIC desenvolvidos por alunos em formação inicial de professores e por professores em formação contínua. Eles queriam ver o encaixe entre as falas dos professores e a realidade observada na prática. Se as intenções são dominadas pela abordagem sócio-construtivista (vimos que as TIC podem 
favorecer tal abordagem), particularmente nas mensagens deixadas nos fóruns de grupo, a realidade é outra: os professores tendem a recorrer aos seus velhos hábitos de aprendizagem.

As Tics mudam o mundo do trabalho e o ambiente escolar, exigem novas habilidades, particularmente no ejido da missão de pesquisa, participação em redes de comunicação: Abordagens sócio-construtivistas de ensino / aprendizagem, como comunidades de aprendizagem em rede (Brown, 1997; Wenger, 1998) são percibidos por diversos pesquisadores da área como uma aventura promissora para repensar o ensino e a aprendizagem de forma a responder melhor às mudanças na sociedade.

A formação colaborativa é um dos critérios de uma abordagem sócio-construtivista, com a redefinição dos papéis que implica (ver capítulos anteriores) para o professor, o aluno e o discernimento. Mas parece que, apesar do discurso sócio-construtivista dos professores em formação, as habilidades cognitivas de alto nível, como análise ou avaliação, são consideradas seu território exclusivo. O discurso é, portanto, ambivalente, mesmo que tenda

para valores sócio-construtivistas. É necessário que os autores desenvolvam uma consciência dessa ruptura nos alunos e desenvolvam práticas reflexivas.

\section{Contribuição das TIC, na formação colaborativa}

Segundo Lipponen (2002), a CSCL (sigla em inglês) teria surgido no início dos anos 90, na continuação do CSCW (trabalho cooperativo assistido por computador) que era mais voltado para o trabalho corporativo. A segunda letra C de "CSCL" pode referir-se a outros termos que não colaborativos, as diferentes possibilidades encontradas foram coletivas, cooperativas, coordenadas. Aqui encontramos a ambigüidade do termo colaborativo, conforme mencionamos na primeira parte. O CSCL usa três campos diferentes: colaboração, mediação de computadores e educação a distância.

CSCLs não são óbvios para definir, não há uma definição clara. É difícil conceber uma dissertação sobre esse conteúdo. Uma vez que os significados são tão diversos (Stahl, Koschmann \& Suthers, 2006): isso pode afetar tanto as crianças no jardim de infância quanto os alunos do ensino superior, educação formal e informal (museus, por exemplo). Para Lipponen, a CSCL está interessada em como o treinamento colaborativo, informado pela tecnologia, pode promover interações entre pares em grupos e como a assistência e a tecnologia proporcionam a troca e disseminação de conhecimento e conhecimento. Deve-se notar que a maior parte da pesquisa é anglo-saxônica.

Nussbaum et al. (2009) explicam que a CSCL não contribui fundamentalmente com nada de novo na concepção intelectual de treinamento colaborativo, mas que as tecnologias utilizadas vêm para apoiar uma operação, uma implementação. Não é a CSCL que faz a 
colaboração, na formação colaborativa é preciso pensar de cima e as ferramentas técnicas permitem organizar melhor os processos. Da mesma forma, não é porque haja colaboração que haverá aprendizado. Os alunos devem participar de um framework bem definido, saber interagir e resolver problemas. Devem ter adquirido tanto conhecimento técnico.

$\mathrm{O}$ alicerce implementado pelas TIC permite que as diferentes etapas se desenvolvam de forma mais fluida e estruturada. O professor fica dispensado de parte do trabalho de direção e pode assim se dedicar mais ao trabalho dos grupos. O diagrama de operação descrito no estudo de Nussbaumet al. (2008) prevê uma progressão do trabalho individual, trabalho em pequenos grupos, trabalho em grande grupo. A constituição aleatória de grupos realizada pelo computador parece ser mais bem aceita pelos alunos do que quando os grupos são impostos pelo professor.

Delache et al. (2006) estudaram diferentes usos de ambientes digitais e analisaram as práticas do que é o treinamento colaborativo em si. Quando se trata de projetos de redação colaborativa, eles notaram que os resultados são positivos quando são duradouros. Há uma grande mudança no papel do tutor, ou pelo menos na relação entre tutor e aluno. Paradoxalmente, o uso de ferramentas digitais fortalece a relação humana e a proximidade entre os atores: A distância física é atenuada pela velocidade das trocas e por uma potencial copresença no espaço virtual. O professor tutor tem um papel primordial e central num sistema de formação online, é ele quem estimula uma dinâmica comunitária e colaborativa. Por outro lado,

Tanto mais que isso implica novos comportamentos por parte do corpo docente: organização, co-design, etc. Na verdade, é uma mudança na cultura profissional. Essa mudança também é observada por Daele e Docq (2002). Para eles, o tutor online, além da função esperada do tutor tradicional (treinamento presencial), deve fornecer suporte nos aspectos técnicos (quais ferramentas utilizar, quando, para que finalidade). A complexidade também se deve ao fato de que é necessário gerenciar uma atividade de grupo dentro de um ambiente escrito. As falhas observadas estão mais ligadas a um problema de relações sociais do que a um problema técnico. Daí a necessidade de uma liderança forte, liderança que pode ser fornecida pelo tutor, mas também por um aluno.

Os pesquisadores levantam a questão da transferência de certas responsabilidades do tutor para os alunos. Em seu estudo, os alunos acham difícil reclamar na relação cara a cara com as pessoas que colaboram com eles. Não vamos estudar mais a CSCL, deveria ser um tópico atual do qual seria o único tópico. No entanto, é um campo em rápida expansão que deve ser monitorado regularmente. 


\section{Para continuar}

É difícil chegar a uma conclusão sobre esse tópico em constante evolução. Seria interessante explorar caminhos adicionais, em particular os movimentos educacionais e movimentos de educação popular. Como os movimentos educacionais se posicionam frente às TIC? Os movimentos pedagógicos ligados à nova educação, métodos ativos, pedagogia Freinet, têm uma longa prática de atividades colaborativas e há muito se empenham em trabalhos de reflexão sobre o trabalho em grupo. No entanto, eles integraram as TIC em suas práticas? Você encontrou usos nessas ferramentas que permitem ir mais longe no treinamento colaborativo? Não focamos este arquivo nesse aspecto, mas a questão parece relevante para nós.

Os movimentos de educação popular também podem integrar as TIC em suas práticas. Boucher-Petrovic (2008), escreve sobre TIC e associações de educação popular: Essas novas possibilidades educacionais e essas promessas ecoam diretamente os valores e abordagens da educação popular, enquanto essas novas formas de desigualdades questionam a relevância do projeto histórico e das práticas da educação popular. Com efeito, apesar de filosofias e origens muito diferentes, certas conexões podem ser estabelecidas entre o projeto de educação e o da comunidade de conteúdo e informação, pelo menos no que diz respeito às potencialidades e promessas desta última.

Alegou-se que as tecnologias de comunicação colaborativa aumentam a colaboração nas estruturas organizacionais, sob certas condições. Essa declaração foi considerada problemática em vários aspectos, também no início das derivações de 18 estudos de caso de uso do Lotus Notes, retirados da literatura. Os casos podem ser divididos em três grupos: (1) uso exploratório, conservador ou cauteloso; (2) uso planejado e em expansão; e (3) uso extensivo e comprometido das Notas. No primeiro grupo, não foram encontradas alterações nas modalidades de trabalho devido à utilização de Notas.

No segundo grupo, as aplicações agendadas do Notes suportavam arranjos de trabalho estabelecidos, tanto colaborativos quanto hierárquicos. Apenas no terceiro grupo houve mudanças significativas no sentido de uma maior colaboração. Essas mudanças foram devidas a um esforço consciente e contínuo para gerar novos arranjos de trabalho e novos tipos de suporte do Notes. Uma série de questões emergiram na revisão que podem ajudar a entender a relação entre as tecnologias de comunicação colaborativa e as mudanças no trabalho e na organização.

Os problemas incluíam o papel dos recursos específicos da tecnologia; a diferença entre tecnologia como produto e tecnologia em uso; o tipo de cuidado necessário para alcançar as mudanças desejadas; a natureza emergente e a tendência do processo de mudança; o papel 
da tecnologia como ferramenta construtiva para improvisar e implementar mudanças; e a tradução gradual das influências das práticas de trabalho para as práticas organizacionais.

Na revisão literária dos estudos colaborativos, surgiram várias questões que podem ajudar a compreender a relação entre as tecnologias de comunicação colaborativa e as mudanças no trabalho e na organização. Os problemas incluíam o papel dos recursos específicos da tecnologia; a diferença entre tecnologia como produto e tecnologia em uso; o tipo de cuidado necessário para alcançar as mudanças desejadas; a natureza emergente e a tendência do processo de mudança; o papel da tecnologia como ferramenta construtiva para improvisar e implementar mudanças; e a tradução gradual das influências das práticas de trabalho para as práticas organizacionais.

A revisão levantou uma série de questões que podem ajudar a compreender a relação entre as tecnologias de comunicação colaborativa e as mudanças no trabalho e na organização.

Os problemas incluíam o papel dos recursos específicos da tecnologia; a diferença entre tecnologia como produto e tecnologia em uso; o tipo de cuidado necessário para alcançar as mudanças desejadas; a natureza emergente e a tendência do processo de mudança; o papel da tecnologia como ferramenta construtiva para improvisar e implementar mudanças; e a tradução gradual das influências das práticas de trabalho para as práticas organizacionais. o tipo de cuidado necessário para alcançar as mudanças desejadas; a natureza emergente e a tendência do processo de mudança; o papel da tecnologia como ferramenta construtiva para improvisar e implementar mudanças; e a tradução gradual das influências das práticas de trabalho para as práticas organizacionais. o tipo de cuidado necessário para alcançar as mudanças desejadas; a natureza emergente e a tendência do processo de mudança; o papel da tecnologia como ferramenta construtiva para improvisar e implementar mudanças; e a tradução gradual das influências das práticas educacionais para as práticas organizacionais e formativas.

Em práticas colaborativas mediadas por computador mostram as interações entre a evolução da prática, a troca de conhecimento e o uso de mídia de computador. Cada artigo destaca o trabalho invisível (Star \& Strauss, 1999) da colaboração mediada por computador, ou seja, o trabalho de aprender a colaborar por meio da mídia computacional e desenvolver um trabalho compartilhado e práticas de comunicação em torno e por meio das tecnologias de comunicação. Trabalhos futuros devem estender e continuar a evolução das práticas colaborativas mediadas por computador, fornecendo mais casos sobre a interação de pessoas, prática e tecnologia, estendendo os princípios que sustentam este tipo de interação e demonstrando o impacto dessas práticas por meio de novas medições abordagens,

Pode-se considerar como os processos coevoluem entre as práticas técnicas e sistemas, como o conhecimento é compartilhado através das fronteiras organizacionais, culturais e 
geográficas, como a conversa através do meio informal de mensagens instantâneas está sendo adotada nas práticas organizacionais, o que motiva a participação na grande computação distribuída projetos. e como a mídia de computador pode mudar a natureza da interatividade nas salas de aula. Os estudos revisados cobrem uma variedade de aplicações e ambientes; como coleção, chamam a atenção para a interpretação ampla que pode ser dada ao significado da colaboração mediada pelas novas tecnologias da informação.

A colaboração mediada por computador se tornou um tema quente devido a várias tendências que mudam a maneira como conduzimos o trabalho organizacional e acadêmico. Primeiro, o aumento do uso de mídia de computador para comunicação diária leva ao aumento da atividade online, mesmo com colegas locais. A comunicação por meio de computadores também é complementada por várias formas de armazenamento de dados, incluindo bancos de dados, bibliotecas digitais e informações armazenadas e disseminadas pela web.

O uso combinado de comunicação mediada por computador e tecnologias de comunicação apresenta novos desafios na expertise do local de trabalho (Professores), incluindo a adoção de novas formas de interação interpessoal (Aluno - professores, por exemplo, e-mail e mensagens instantâneas), novas práticas de troca de informações (por exemplo, empacotamento de informações para ajustar os campos da plataforma de dados e depósito de informações online) e novos horários de interação educacional.

O alcance da Internet abre e incentiva a colaboração entre pessoas separadas pela distância geográfica. Conforme o trabalho se expande globalmente, também aumentam as discrepâncias na cultura, idioma, origens e práticas de trabalho daqueles que colaboram. Trabalhar nessas divisões é desafiador quando elas são óbvias, mas os funcionários geralmente não estão preparados para essas diferenças. À medida que desenvolve suas práticas de trabalho em conjunto, você primeiro descobre as diferenças e, em seguida, aprende e adota maneiras de lidar com essas diferenças.

Muitos novos tipos de pesquisa e prática organizacional requerem a combinação de conhecimento especializado de toda as divisões de trabalho, práticas disciplinares acadêmicas e comunidades de prática. Reunir classificações, disciplinas e comunidades educacionais envolve reunir e compartilhar conhecimentos sobre as práticas formativas de outras pessoas, bem como criar um conhecimento comum. A necessidade de cruzar tais divisões convocou a aplicação nos contratempos da transferência de conhecimento, incluindo como explicitar o conhecimento tácito e como trabalhamos com o conhecimento que temos, testando-o com as facilidades e frustrações do mundo.

Os desafios para este tipo de trabalho passam por criar um terceiro espaço para ver também onde novos vocabulários e significados compartilhados são determinados. Esses 
espaços também permitem outros tipos de aprendizagem, por exemplo, sobre quem sabe o quê. Eles também permitem o desenvolvimento e o compartilhamento de práticas, em parte pelo design e em parte pela interação dos colegas de trabalho com a "facilidade e frustração" dos pontos de vista dos outros, a tecnologia com a qual trabalham e os problemas que enfrentam. Não é um processo estático e único, mas uma evolução contínua das práticas à medida que as pessoas interagem com as demandas de trabalho, aprendizagem e conhecimento, equilibrando-as com quem e com quais recursos trabalham.

Os temas abordam a evolução da natureza da colaboração com e por meio da mídia de computador e com outras pessoas, locais e remotas. A questão de compreender a evolução de novas práticas, baseadas nos meios informáticos e confundidas com distribuições em geografia, cultura e conhecimento, está no centro de cada um dos artigos aqui apresentados. O exame das práticas colaborativas mediadas por computador é baseado no trabalho em muitas áreas, incluindo comunicação mediada por computador, computação social, trabalho cooperativo assistido por computador e gestão do conhecimento, mas é caracterizado pela atenção aos processos Interativos que levam a percepções compartilhadas e emergentes e práticas. 


\section{Referências}

Baudrit Alain (2005). Aprendizado cooperativo. Origens e desenvolvimentos de um método de ensino. Bruxelas: De Boeck.

Baudrit Alain (2007). Aprendizagem colaborativa: mais do que um método coletivo? Bruxelas: De Boeck. Boucher - Pagetrovic Natalie (2008). Ferramentas digitais na educação popular. Em dias de aprendizado e comunicação em rede. Paris: Hermes Lavoisier.

Boyd, D. (2008). Retirado do contexto: American Teen Sociality in Networked Audiences. Berkeley: University of California, Philosophy.

Buffa, M. (2008). Da web aos wikis: uma história de ferramentas colaborativas.

Breton, P. (2001). O culto da Internet. Paris: a descoberta.

Bruns, A. (2007) O futuro é orientado pelo usuário: o caminho para a produção generalizada. Revista de cultivo de fibra.

Cucchi, M. (2003). Nota de leitura: cibercultura.

Chaptal A. (2007). Usos anunciados, usos observados. Reflexão sobre o uso escolar da tecnologia por professores.

Chaptal Alain (2009). Rapsódia sobre colaboração: trabalho colaborativo. Os arquivos educacionais.

Cress, J. e Kimmerle, J. (2008). Uma visão sistêmica e cognitiva sobre a construção colaborativa do conhecimento com wikis. International Journal of Computer Aided Collaborative Learning.

Delache D., D'Halluin, C. e Fichez, E. et al. (2006). Ambientes digitais e práticas de aprendizagem colaborativa. Relatório de fim de investigação sobre operação de PCDAI financiada pelo Ministro encarregado da investigação.

Dillenbourg, P. (1999). O que você quer dizer com aprendizagem colaborativa? Em Dillenbourg P. aprendizagem colaborativa: abordagens cognitivas e computacionais. Oxford: Elsevier.

Ducate Lara, C. e Lomicka LC (2008). Explorando a blogosfera: uso de registros da web na sala de aula de língua estrangeira. Aprendizagem de línguas auxiliada por computador.

Dumont, C. (2007). Implementação técnica: As plataformas. Em Manderscheid Jean-Claude e Jeunesse Christophe. Educação online: na universidade e na formação profissional. Bruxelas.

Endrizzi, L. (2006). A edição de referência gratuita e colaborativa: o caso da Wikipedia.

Ferris P., S. e Wilder H. (2006). Usos e potencialidades dos wikis em sala de aula, Inovação. Guell, S. e Wiley, D. (2008). Manual de recursos educacionais abertos 1.0. Educador Wiki.

Gueudet G. \& Trouche L. (2009) Desenho e uso de recursos para e por professores. Desenvolvimento associativo e desenvolvimento profissional: Trabalho colaborativo. Registros de engenharia educacional. 
Gharsallah, M. (2007). "Internet e inteligência coletiva". In the Internet and Collective Intelligence, 19 de maio de 2007. Tence: Tence University.

Levys Pierress (1997). Inteligência combinada. Uma antropologia do espaço virtual. Paris: a descoberta. Laeboucq Brice (2001). Notas de leitura: Internet. Estudos, voo. Laippone Lasse (2002). Explorando os fundamentos da aprendizagem colaborativa assistida por computador. Em CSCL Proceedings, Boulder, Colorado, EUA, 7 a 11 de janeiro de 2002. Lawrence Erlbaum Associates, Inc.

Lippone, L. (2002). Explorando os fundamentos da aprendizagem colaborativa assistida por computador em procedimentos CSCL. Colorado, EUA

Mallein, P. (2009). Pense paradoxal para inovar de outra maneira. Em Como co-produzir e organizar o conhecimento? Autrans, 7 a 9 de janeiro de 2009.

Manderscheid, J., C. e Jeuness C. (2007). Educação online: na faculdade e em treinamento competitivo. Porque? Como? 'O que? Bruxelas: De Boeck.

Mishel, C., Garrot, E. e George, S. (2007). Situações de aprendizagem coletiva instrumentada: Estudo das práticas no ensino superior. Distâncias e conhecimento.

Mejias, U. (2006). Ensino de Software Social com Software Social de Inovação.

Moiraud Jean-Paul (2009). "Trabalho colaborativo na seção de diploma superior de artes aplicadas. Arquivos de engenharia educacional.

Montuori, C., Breda I, Ducreux, A. e Serverton T. (2008). O uso das TIC na sala de aula: entre a relutância e a ignorância. Nos dias de aprendizagem e comunicação em rede.

Nussbaum, M., Álvarez C. e MC Farlane, A. et al. (2009) Tecnologia como um andaime colaborativo face a face em um pequeno grupo. Ciência da computação e educação.

Pisani, F. \& Piotet, D. (2008). Como a Web está mudando o mundo: a alquimia das multidões. Paris: Pearson.

Sauter, M. Combes, MC e De Crozals, A., et al. (2008) Uma comunidade de professores para pesquisa colaborativa de problemas.

Simeone, A., Eneau J. e Rinck F. (2007). Cenário de aprendizagem colaborativa online: habilidades relacionais exigidas e desenvolvidas. Informação, conhecimento, decisões e mediações.

Stahl G. (2009). Sim podemos! Aprendizagem colaborativa auxiliada por computador.

Viens, J. e Rioux, S. (2002). Da difícil atualização dos princípios pedagógicos sócioconstrutivistas. Em Karsenty Thierry e Larose François. O lugar das TIC na formação contínua e inicial. Sherbrooke.

Wijnen, W. (2001). Aprendizagem colaborativa, outubro. Online: adicionado por: Rémi Thibert. Paris). 